\title{
A CASE OF AN ADENOMA ARISING IN A SWEAT GLAND OF THE UPPER EYELID*
}

BY

\author{
F. Clifton and W. H. GORDON
}

LONDON

REPORTS of adenomata of the sweat glands are perhaps sufficiently rare to justify the description of a case where features are thought to indicate some points in the clinical diagnosis of these tumours.

Mrs. A.B., aged 70 years, seen recently as an Out-Patient, presented for examination a tumour of the left upper lid which had been increasing in size slowly over a period of five years. Clinical details of the early appearance of the lesion are not available, but it is known that the provisional diagnosis of ? sebaceous adenoma ? rodent ulcer, was made some time ago. The original lesion appears to have presented as a small crust on the skin of the lid near the inner canthus and adjacent to the margin..

On examination, there was present a rather flattened oval tumour with the long axis vertical, the lower pole of which overhung the lid margin, shielding also part of the caruncle from view. In size $1 \mathrm{~cm}$. long and $\frac{3}{4} \mathrm{~cm}$. broad, the smooth growth was covered by somewhat stretched though otherwise normal skin, movable over the tumour as a whole, but attached around the slightly raised edges of a small para-central crusted area. On palpation, the growth felt firm, yet not as hard as would have been expected in the case of an epithelioma. There was no regional glandular involvement and the tumour transilluminated freely.

Operation was performed by Mr. Eugene Wolff. A skin incision was made across the growth, which encapsulated in a thin fibrous sheath, was dissected out en masse, without difficulty. Small strips of redundant skin were removed from the margins of the incision which was closed by one silk suture. Healing was uneventful and rapid. The cosmetic result was very good, the lid appearing normal, save for the presence of a minute horizontal scar detectable on close examination.

Reference to the literature indicates that, in the past, extensive resections of the lid have been performed, with the necessity for subsequent plastic repair.

Pathology.-The skin is stretched over a tumour resembling in structure a tubulo-racemose gland. From the fibrous capsule, which is quite definite, except where the over-lying skin is

* Received for publicatín, June 4, 1947. 
ulcerated, septa carrying well-formed vessels pass inwards to divide the tumour into lobules, and in turn give rise to finer strands supporting the branching tubules. In many places the fibres of this stroma are curiously swollen and ill-defined, occasionally so greatly that no structure can be made out, and the walls of many

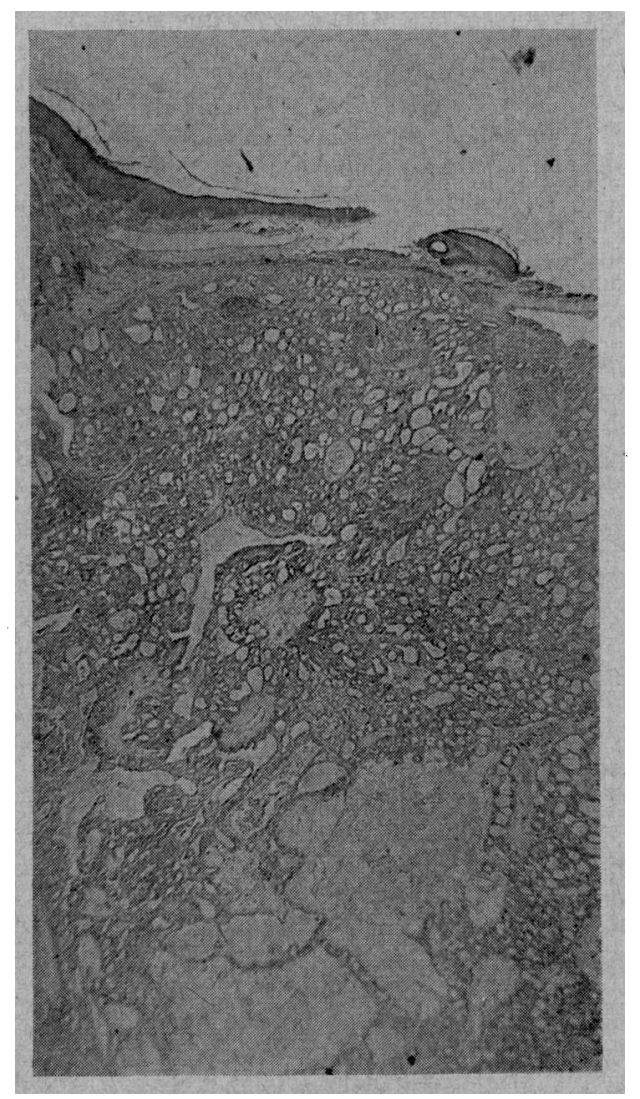

FIG. 1.

Low power view showing the fibrous capsule and the numerous cysts.

of its blood vessels are similarly affected. The stroma is also infiltrated by lymphocytes which, here and there, form follicles.

Whilst in general the structure is tubular, in places there is proliferation of the parenchymal cells as solid masses, between some of whose cells cell-bridges can be made out. In these cellmasses are many degenerative cysts in all stages of development, from minute to quite large ones. 


\section{ADENOMA ARISING IN A SWEAT GIAND OF THE UPPER EYELID 699}

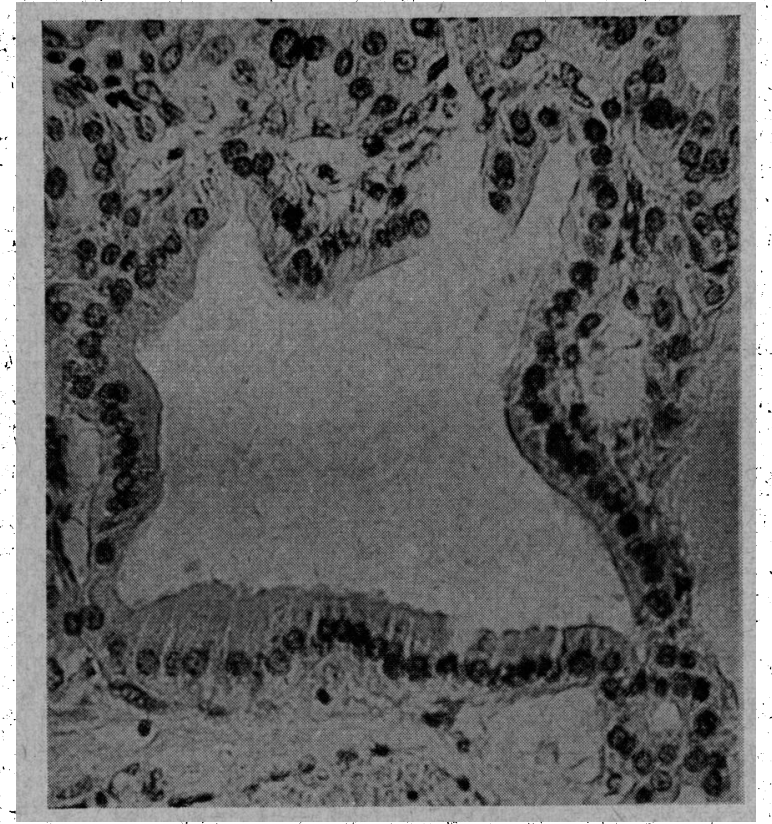

FIG. 2.

High power view of a cyst of type (1).

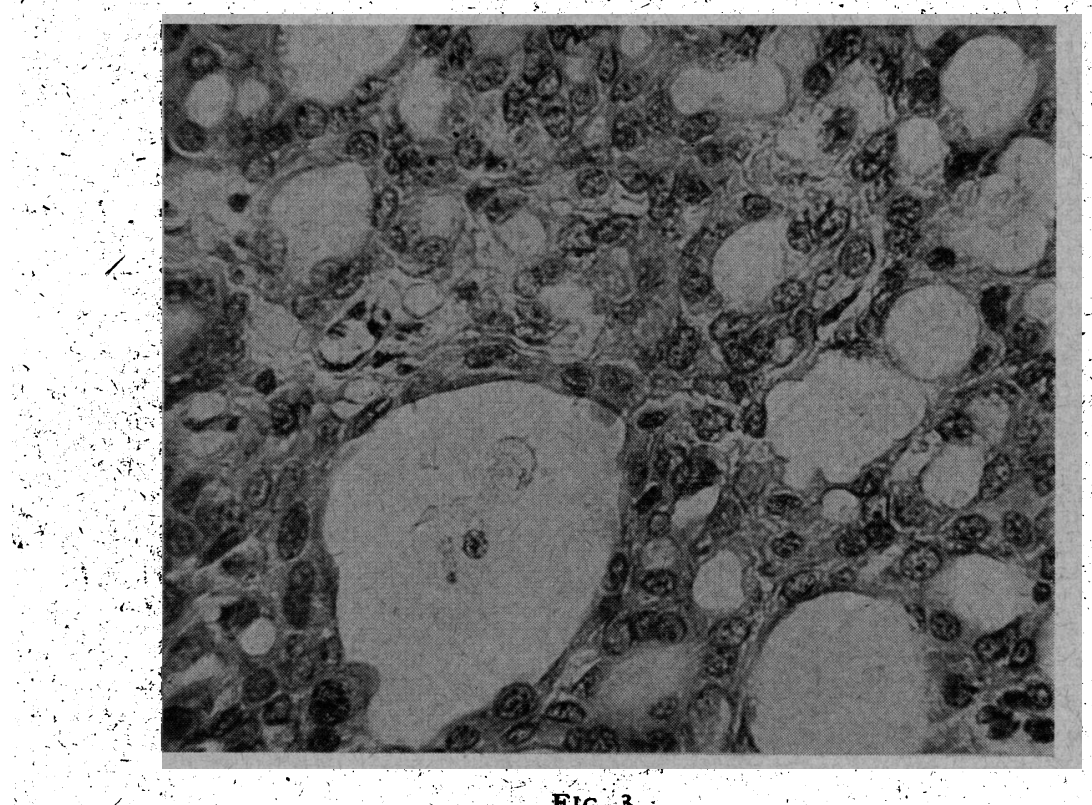

High power view of cysts (pseudocysts) of type (3). Degenerated tumaur cells are seen within these. 
A section of the tumour shows spaces or "cysts" of the following three types:-

(1) Lumina of tubules lined by columnar epithelium similar to that of the normal sweat gland, and having sometimes also an outer layer of cubical cells with oval nuclei which probably represent the myoepithelial cells of the normal gland.

(2) Lumina lined by smaller altered gland cells having denser nuclei.

(3) Cystic spaces due to breakdown of tissue cells, lined by partly degenerated polyhedral cells or in places merely walled by the stroma, and containing an albuminous coagulum and occasionally disintegrating parenchymal cells.

\title{
Summary
}

A case of adenoma of a sweat gland has been described and it is suggested that if consideration be given to the long history, the presence of the crust, the mobility of the skin over the edges of the tumour, the translucency, and the'firm consistency, perhaps best tested with the blunt end of a probe for cystic spaces, a clinical diagnosis of this condition should be possible.

\section{AN UNUSUAL CASE OF SYMMETRICAL, BILATERAL, NON-TRAUMATIC IRIS PROLAPSE.}

B Y

\author{
M. L. NaIRAC \\ MAURITIUS
}

A NEGRO woman aged 22 years, was transferred from the island of Rodriguez to the Civil Hospital, Port Louis, Mauritius, on March 29, 1947.

I here quote the report of the Government Medical Officer who first saw the case.

"Two weeks before she was seen, on March 15, she felt a strong, burning pain in the right eye followed by a discharge of 'pus.' The following day the left eye became similarly affected. The pain was such that the patient could not open her eyes and in her own words was blind for a few days."

"When first seen the patient was suftering from intense photophobia. Both eyes were found to have a staphyloma in the upper quadrant, the right side greater than the left. The pupils were irregular and drawn up. The walls of the herniation were so thin

\footnotetext{
* Received for publication, May 26, 1947.
} 